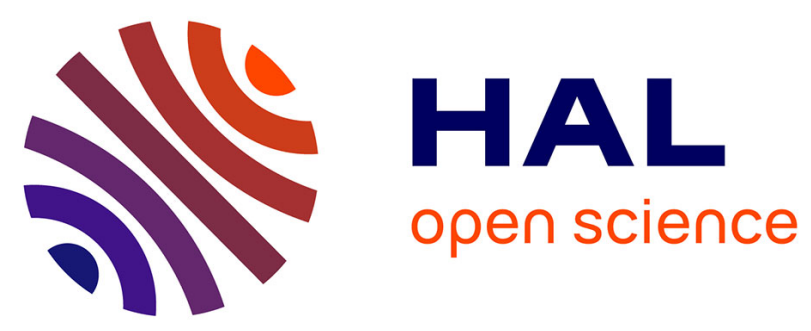

\title{
Expedient Mechanosynthesis of N,N-Dialkyl Imidazoliums and Silver(I)-Carbene Complexes in a Ball-Mill
}

\author{
Audrey Beillard, Ethan Golliard, Valentin Gillet, Xavier Bantreil, \\ Thomas-Xavier Métro, Jean Martinez, Frédéric Lamaty
}

\section{To cite this version:}

Audrey Beillard, Ethan Golliard, Valentin Gillet, Xavier Bantreil, Thomas-Xavier Métro, et al.. Expedient Mechanosynthesis of N,N-Dialkyl Imidazoliums and Silver(I)-Carbene Complexes in a Ball-Mill. Chemistry - A European Journal, 2015, 21 (49), pp.17614-17617. 10.1002/chem.201503472 . hal02364136

\section{HAL Id: hal-02364136 \\ https://hal.science/hal-02364136}

Submitted on 2 Feb 2021

HAL is a multi-disciplinary open access archive for the deposit and dissemination of scientific research documents, whether they are published or not. The documents may come from teaching and research institutions in France or abroad, or from public or private research centers.
L'archive ouverte pluridisciplinaire HAL, est destinée au dépôt et à la diffusion de documents scientifiques de niveau recherche, publiés ou non, émanant des établissements d'enseignement et de recherche français ou étrangers, des laboratoires publics ou privés. 


\title{
Mechanochemistry
}

\section{Expedient Mechanosynthesis of $N, N$-Dialkyl Imidazoliums and Silver(I)-Carbene Complexes in a Ball-Mill}

\author{
Audrey Beillard, Ethan Golliard, Valentin Gillet, Xavier Bantreil,* Thomas-Xavier Métro,* \\ Jean Martinez, and Frédéric Lamaty ${ }^{*[a]}$
}

Dedicated to the memory of Dr. Guy Lavigne

\begin{abstract}
The absence of solvent, associated with intensive mechanical agitation, allowed the first mechanosynthesis of high-value silver(I)-carbene complexes and the corresponding $\mathrm{N}, \mathrm{N}$-dialkylimidazolium precursors. This procedure gave outstanding results in terms of yield and reaction time, when compared to solution-based conditions previously described in literature, and was generalized to unprecedented compounds. Silver(I)-carbene complexes could either be obtained from $\mathrm{N}, \mathrm{N}$-dialkylimidazolium salts or directly from imidazole and alkyl halides in a one-pot two-step procedure without isolating the imidazolium intermediate. Additionally, an efficient one-pot three-step sequence, including imidazole alkylation, silver metalation, and transmetalation is reported.
\end{abstract}

In addition to their remarkable anticancer and antimicrobial properties, ${ }^{[1]}$ silver(I)-carbene complexes $([\mathrm{Ag}(\mathrm{NHC}) \mathrm{X}])$ are recognized as a universal platform for the generation of organometallic complexes. ${ }^{[2]}$ This can be explained both by the great diversity of $\mathrm{N}$-heterocyclic carbenes (NHCs) and a wide range of metals that could be used. Besides, $[\mathrm{Ag}(\mathrm{NHC}) \mathrm{X}]$ complexes bearing $\mathrm{N}, \mathrm{N}$-dialkyl-substituted $\mathrm{NHCS}$ have proved to have interesting biological activities ${ }^{[1 a]}$ and electroluminescent properties. ${ }^{[3]}$ However, $[\mathrm{Ag}(\mathrm{NHC}) \mathrm{X}]$ complexes suffer from chemo- and photosensitivity, and their production requires long reaction times and/or excess reagents. In the literature, their syntheses are mostly performed in $\mathrm{CH}_{2} \mathrm{Cl}_{2}$, a highly volatile organic solvent suspected of causing cancer as indicated by the GHS classification. The corresponding imidazolium halide precursors were mostly obtained through alkylation of imidazoles, with extended reaction times at refluxing temperatures. A convenient way to increase the efficiency and to reduce the environ-

\footnotetext{
[a] A. Beillard, ${ }^{+}$E. Golliard, ${ }^{+}$V. Gillet, Dr. X. Bantreil, Dr. T.-X. Métro, Prof. Dr. J. Martinez, Dr. F. Lamaty

Institut des Biomolécules Max Mousseron (IBMM), UMR 5247

CNRS, Université Montpellier, ENSCM, Université de Montpellier

Place Eugène Bataillon, 34095 Montpellier cedex 5 (France)

E-mail:xavier.bantreil@umontpellier.fr

txmetro@umontpellier.fr

frederic.lamaty@umontpellier.fr

$\left.{ }^{[+}\right]$These authors contributed equally to this work.
}

mental impact of such reactions is to use solvent-free mechanosynthesis. ${ }^{[4]}$ While the benefits of mechanochemistry have already been demonstrated for the generation of organometallic complexes, ${ }^{[5]}$ the mechanosynthesis of $\mathrm{N}, \mathrm{N}$-dialkylimidazolium halides and their corresponding $[\mathrm{Ag}(\mathrm{NHC}) \mathrm{X}]$ complexes has never been reported. As an extension of our studies on mechanochemistry for organic synthesis ${ }^{[6]}$ and generation of Pd nanoparticles, ${ }^{[7]}$ we detail herein the advantages of using a mechanochemical approach for the production of widely used $\mathrm{N}, \mathrm{N}$-dialkylimidazolium salts and valuable $[\mathrm{Ag}(\mathrm{NHC}) \mathrm{X}]$ complexes (Scheme 1).

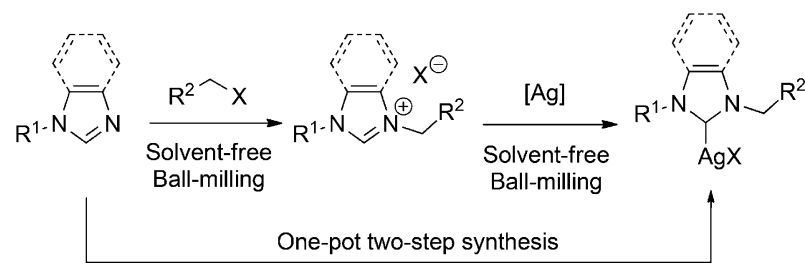

Scheme 1. Strategy for the mechanosynthesis of $[\mathrm{Ag}(\mathrm{NHC}) \mathrm{X}]$.

Initially, we focused on the synthesis of $\mathrm{N}, \mathrm{N}$-dialkylimidazolium salts, which were obtained by nucleophilic substitution of alkyl halides with $\mathrm{N}$-alkyl imidazoles. Unless noted otherwise, all reactions were realized without solvent in a $10 \mathrm{~mL}$ stainless steel reactor containing a $10 \mathrm{~mm}$ diameter stainless steel ball that was placed under agitation at $25 \mathrm{~Hz}$ in a vibratory ball-mill (vbm). The reaction mixtures were recovered and treated with preferable solvents, such as $\mathrm{EtOH}, \mathrm{PrOH}$, or EtOAc/water. ${ }^{[8]}$ Subsequent filtration allowed elimination of any metallic particles and isolation of pure products. ${ }^{[6]]}$ For comparison, the best results reported in the literature for experiments performed in solution have been included (Table 1).

The reaction of benzylbromide with $\mathrm{N}$-methyl- and $\mathrm{N}$-isopropyl-imidazole yielded imidazoliums $1 \mathrm{a} \cdot \mathrm{HBr}$ and $\mathbf{1 b} \cdot \mathrm{HBr}$, respectively, in more than $98 \%$ within only $1 \mathrm{~h}$ (Table 1, entries 1 and 2). Interestingly, the synthesis of $\mathbf{1 a} \cdot \mathbf{H B r}$ was performed with the same efficiency on a $4 \mathrm{~g}$ scale, using a $250 \mathrm{~mL}$ reactor agitated in a planetary ball-mill (pbm). Bidentate ligand precursors $\mathbf{2 a} \cdot \mathbf{H B r}$ and $\mathbf{2 b} \cdot \mathbf{H B r}$, featuring a pyridine and an imidazolium moiety, respectively, were synthesized in $1 \mathrm{~h}$ and isolated in excellent yields (>97\%, Table 1, entries 4 and 5). In this case, the use of $\mathrm{NaHCO}_{3}$ (1.5 equiv) was necessary to deprotonate 2(bromomethyl)pyridine hydrobromide and obtain satisfactory 


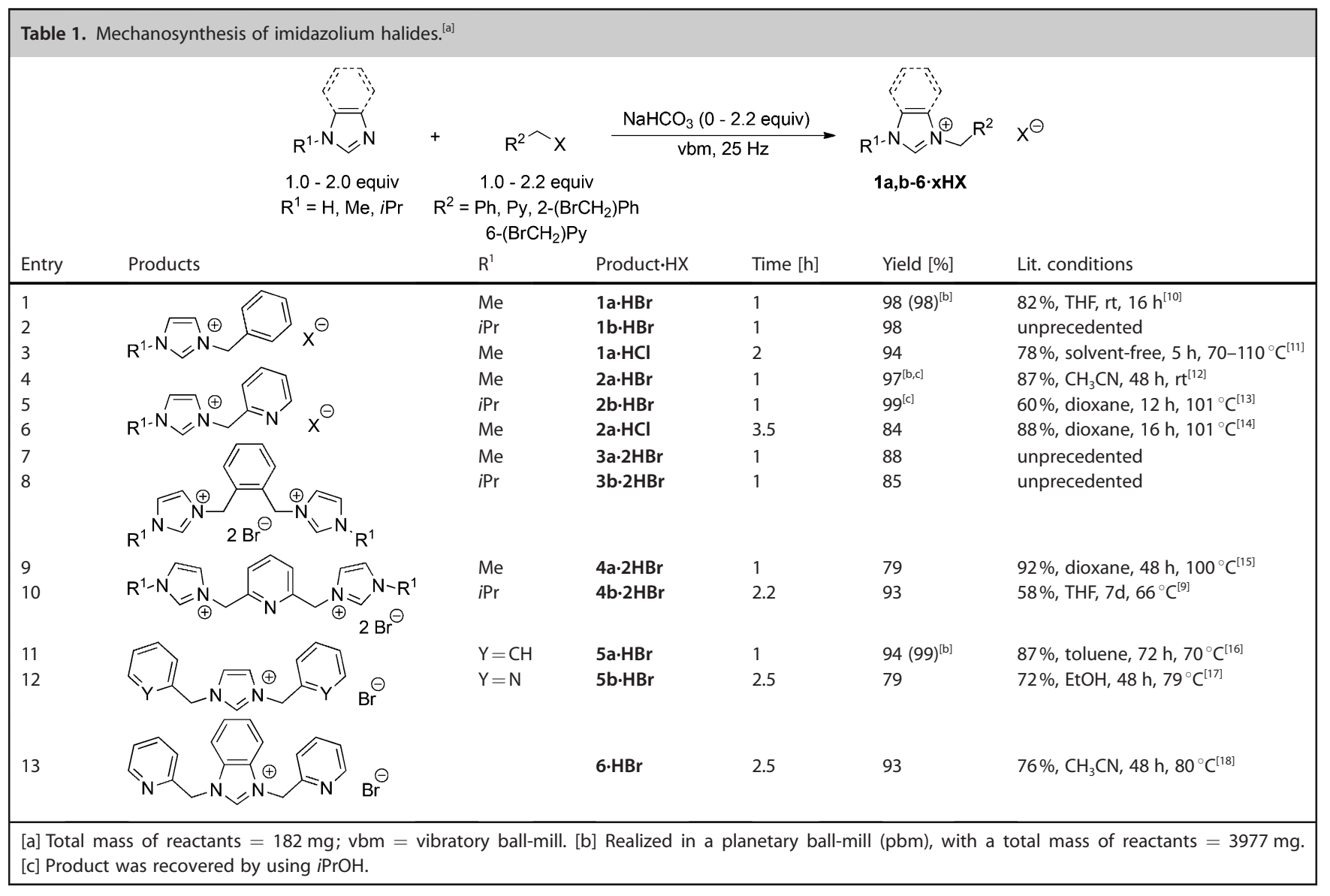

results. Less reactive alkyl chlorides were also mechanically converted into imidazoliums $\mathbf{1 a} \cdot \mathbf{H C l}$ and $2 \mathrm{a} \cdot \mathrm{HCl}$, with slightly longer reaction times $(<3.5 \mathrm{~h})$. When 1,2-bis(bromomethyl)benzene and 2,6-bis(bromomethyl)-pyridine were used as the starting reagents, unreported bis-imidazoliums $3 \mathrm{a} \cdot 2 \mathrm{HBr}$, $3 b \cdot 2 \mathrm{HBr}, 4 a \cdot 2 \mathrm{HBr}$, and $\mathbf{4 b} \cdot 2 \mathrm{HBr}$, were obtained in a very efficient manner. The advantage of mechanochemistry was especially highlighted with $\mathbf{4 b} \cdot \mathbf{2} \mathbf{H B r}$, as only $2.2 \mathrm{~h}$ of milling was necessary to isolate this product in $94 \%$ yield, while 7 days in refluxing THF were required for a literature procedure (isolated in $58 \%$ yield). ${ }^{\left[{ }^{[9]}\right.}$ The reaction of imidazole/benzimidazole with benzyl bromide or 2-(bromomethyl)pyridine hydrobromide in the presence of $\mathrm{NaHCO}_{3}$ proved that this ball-milling procedure could also be extended to symmetrical imidazolium salts. Thus, compounds $5 \mathrm{a} \cdot \mathrm{HBr}, \mathbf{5 b} \cdot \mathrm{HBr}$, and $\mathbf{6} \cdot \mathrm{HBr}$ were isolated with improved yields compared with the previous methods (entries 11-13).

Notably, imidazoliums $\mathbf{1 a} \cdot \mathbf{H B r}$ and $\mathbf{5 a} \cdot \mathbf{H B r}$ were produced in similar yields when synthesized in a vbm or in a pbm, showing that the type of agitation has no influence on the efficiency of the approach (Table 1, entry 1 and 11). While a solvent-based synthesis of $\mathbf{1 a - 6 \cdot x H X}$ salts previously described in the literature required adaptation of the conditions for each compound, such as long reaction times (up to 7 days), in some cases refluxing solvents, the use of ball-mill and solvent-free conditions provides a general, user-, and eco-friendly method to obtain imidazoliums with improved yields and dramatically reduced reaction times. ${ }^{[19]}$ The superiority of solvent-free mechanosynthesis over classical solution-based approaches can be explained by the higher reagent concentrations, which, in combination with an efficient mixing that avoids mass transfer limitations, results in higher reaction rates. In addition, the majority of the $\mathrm{N}, \mathrm{N}$-dialkylimidazolium mechanosyntheses presented in this study required at least one liquid reagent. The capacity of a liquid to present a greater reactive surface area to other reagents and to potentially serve as a solvent ${ }^{[20]}$ appears to us as a good rationale, in this case, to explain the higher efficiency of this approach. This methodology proved general, as numerous mono-, di-, and tridentate ligand precursors were produced.

The synthesis of the corresponding silver(I)-carbene complexes was next envisaged by the reaction of imidazoliums 1a$6 \cdot x H X$ with silver(I) oxide in a vibratory ball-mill under solventfree conditions. Thus, metalation of $\mathbf{1 a} \cdot \mathbf{H B r}$, which was reported to last $24 \mathrm{~h}$ in solution, was completed within only ten minutes under milling, furnishing $[\mathrm{Ag}(1 \mathrm{a}) \mathrm{Br}]$ in $93 \%$ yield (Table 2, entry 1 ). In this case, the higher efficiency of mechanochemical synthesis over a solution-based approach could be attributed to the higher rate of creation of new surfaces on $\mathrm{Ag}_{2} \mathrm{O}$ particles caused by impacts and shear stress induced by ball-milling. ${ }^{[20,21]}$ With this efficient method in hand, various complexes, known or unprecedented, were synthesized. After milling, the reaction mixtures were recovered with $\mathrm{CH}_{2} \mathrm{Cl}_{2}$, filtered over celite and concentrated under vacuum. ${ }^{1} \mathrm{H}$ NMR 


\begin{tabular}{|lllllll}
\hline Table 2. Mechanosynthesis of $[\mathrm{Ag}(\mathrm{NHC}) \mathrm{X}]$ complexes. \\
& & &
\end{tabular}

analysis of the crude mixtures revealed complete conversion of the substrates and high purity of the products in all cases. Except for complexes $[\mathrm{Ag}(\mathbf{2 a}) \mathrm{Cl}]$ and $\left[\mathrm{Ag}_{2}(\mathbf{4 b}) \mathrm{Br}_{2}\right]$ (Table 2, entries 6 and 10), all previously described silver(I)-carbene complexes were obtained in similar or improved yields and reduced reaction times (entries 3, 4, 11, and 12). This particular activation method also allowed the synthesis of five unprecedented silver(I)-carbene complexes (entries 2, 5, 8, 9, and 13). Imidazoliums $\mathbf{2} \mathbf{a} \cdot \mathbf{H X}, \mathbf{2} \mathbf{b} \cdot \mathbf{H X}$, and $\mathbf{5 b} \cdot \mathbf{H B r}$, which contain at least one pyridine ring, required longer milling times (up to $2.5 \mathrm{~h}$ ) than their phenyl-containing congeners $\mathbf{1 a} \cdot \mathbf{H X}, \mathbf{1} \mathbf{b} \cdot \mathbf{H X}$, and $5 \mathrm{a} \cdot \mathrm{HBr}(<1 \mathrm{~h}$, entries $4-6$ and 12 versus $1-3$ and 11$)$. The reaction of $3 a \cdot 2 \mathrm{HBr}$ with $\mathrm{Ag}_{2} \mathrm{O}$ did not yield the expected $\left[\mathrm{Ag}_{2}(3 \mathrm{a}) \mathrm{Br}_{2}\right]$ but led to the formation of an insoluble solid, which was postulated to be an organometallic polymer (entry 7). Similar issues were also observed for $\left[\mathrm{Ag}_{2}(\mathbf{4 a}) \mathrm{Br}_{2}\right]$, which was obtained in irreproducible yields (entry 9). However, the presence of a more hindered $\mathrm{Pr}$ substitution inhibited side reactions, thus $\left[\mathrm{Ag}_{2}(\mathbf{3 b}) \mathrm{Br}_{2}\right]$ and $\left[\mathrm{Ag}_{2}(\mathbf{4 b}) \mathrm{Br}_{2}\right]$ were isolated in 83 and $77 \%$ yield, respectively (entries 8 and 10). It is worth noting that this approach proved to be particularly robust as high yields were obtained independently from various parameters known to have critical influence in solvent-free or solventless mechanochemical reactions, such as relative humidity, type and intensity of milling, physical aspects of the reagents, and reaction mixture. ${ }^{[22]}$

To confirm the structures of the $[\mathrm{Ag}(\mathrm{NHC}) \mathrm{X}]$ complexes obtained by this original mechanochemical approach, several compounds were recrystallized in a $\mathrm{CH}_{2} \mathrm{Cl}_{2}$ /pentane mixture and single crystals were submitted to $\mathrm{X}$-ray diffraction analysis. Thus, unprecedented $[\mathrm{Ag}(\mathbf{1 b}) \mathrm{Br}]$ was confirmed to be a bis$\mathrm{NHC}$ silver cationic complex $\left[\left\{\mathrm{Ag}(\mathbf{1} \mathbf{b})_{2}\right\}^{+} \mathrm{AgBr}_{2}{ }^{-}\right]_{2}$ in which the counter anion $\mathrm{AgBr}_{2}{ }^{-}$forms a dimer (Figure 1). ${ }^{[28]}$

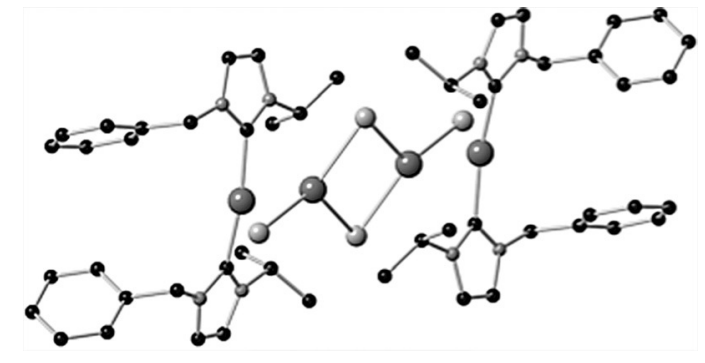

Figure 1. Graphical representation of $\left[\left\{\mathrm{Ag}(\mathbf{1} \mathbf{b})_{2}\right\}^{+} \cdot \mathrm{AgBr}_{2}{ }^{-}\right]_{2} \cdot \mathrm{H}$ atoms are omitted for clarity.

We next envisioned to further demonstrate the efficiency of this novel approach by performing the synthesis of $[\mathrm{Ag}(\mathrm{NHC}) \mathrm{X}]$ complexes in a one-pot sequential alkylation/metalation procedure starting from imidazoles. This technique was very efficient for some $[\mathrm{Ag}(\mathrm{NHC}) \mathrm{X}]$ complexes, such as $[\mathrm{Ag}(\mathbf{1 a}) \mathrm{Br}]$ and [Ag(1b)Br] (Table 3, entries 1 and 2). Interestingly, complexes

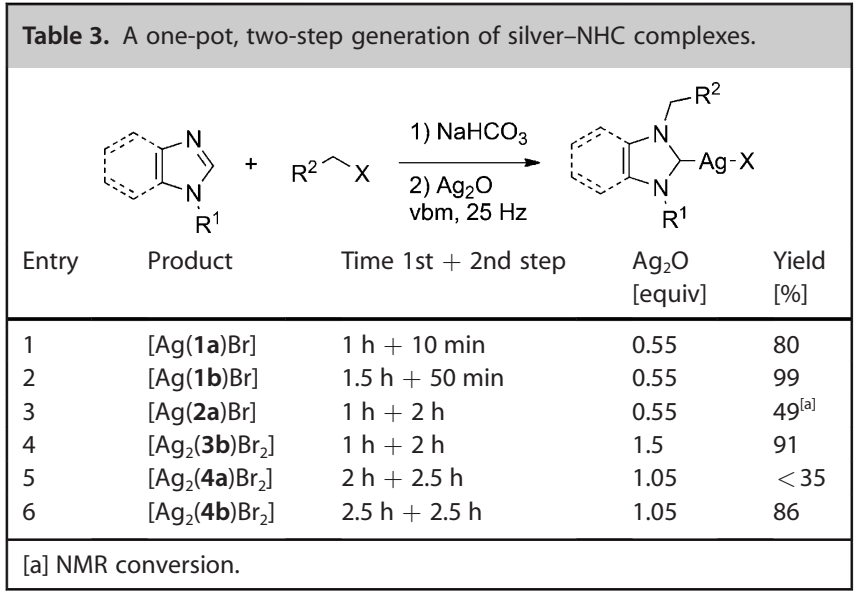

$\left[\mathrm{Ag}_{2}(3 \mathbf{a}) \mathrm{Br}_{2}\right]$ and $\left[\mathrm{Ag}_{2}(\mathbf{4 b}) \mathrm{Br}_{2}\right]$ were obtained with improved yields when synthesized by this one-pot procedure compared to the conditions reported in Table 2 (entry 4 and 6). However, the isolation of $\left[\mathrm{Ag}_{2}(\mathbf{4 a}) \mathrm{Br}_{2}\right]$ was still difficult (vide supra; entry 5).

The usefulness of mechanochemistry in organometallic synthesis was further demonstrated by reacting $[\mathrm{Ag}(\mathbf{1 a}) \mathrm{Br}]$ with $\left[\mathrm{AuCl}\left(\mathrm{SMe}_{2}\right)\right]$ (Scheme 2). The transmetalation occurred within 30 min, yielding complex $[\mathrm{Au}(1 \mathrm{a}) \mathrm{Cl}]$ in $85 \%$, thus completing

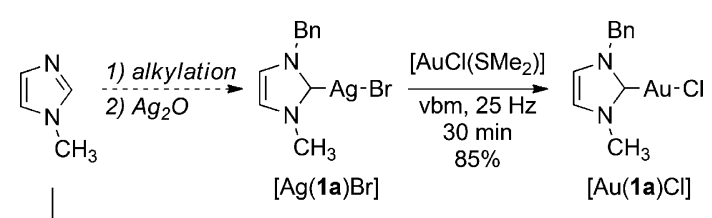

1) $\mathrm{PhCH}_{2} \mathrm{Br}, 1 \mathrm{~h}$
2) $\mathrm{Ag}_{2} \mathrm{O}, 10 \mathrm{~min}$
$\begin{aligned} & \text { 3) }[\mathrm{AuCl}(\mathrm{THT})], 30 \mathrm{~min} \\ & \mathrm{vbm}, 25 \mathrm{~Hz}\end{aligned}$

Scheme 2. Direct and sequential mechanosyntheses of $[\mathrm{Au}(1 \mathrm{a}) \mathrm{Cl}]$. 
a series of three consecutive chemical steps performed in a ball-mill with high efficiency. Moreover, $[\mathrm{Au}(1 \mathrm{a}) \mathrm{Cl}]$ could also be obtained directly from $\mathrm{N}$-methylimidazole in a one-pot three-step procedure, thus avoiding the use of solvents for the isolation of intermediates. In only $1 \mathrm{~h}$ and $40 \mathrm{~min},[\mathrm{Au}(1 \mathrm{a}) \mathrm{Cl}]$ was isolated with a $47 \%$ overall yield $(78 \%$ average yield for each step).

In conclusion, we have demonstrated that ball-milling represents the method of choice for an expedient synthesis of $\mathrm{N}, \mathrm{N}$ dialkyl-substituted NHC precursors and their corresponding $[\mathrm{Ag}(\mathrm{NHC}) \mathrm{X}]$ complexes. Time-saving one-pot/two-step and one-pot/three-step procedures allowed the direct production of silver(I)- and gold(I)-carbene complexes from the imidazole and alkyl halides without the isolation of intermediates, hence, paving the way for further one-pot multi-step mechanosyntheses of organometallic complexes.

\section{Acknowledgements}

Université Montpellier and CNRS are acknowledged for funding. We thank Prof. J.-M. Campagne and the AM2N team for generously providing $\left[\mathrm{AuCl}\left(\mathrm{SMe}_{2}\right)\right]$, and $\mathrm{Dr}$. S. Richeter and the IMNO team for $[\mathrm{AuCl}(\mathrm{THT})]$. F. Métro is warmly acknowledged for the production of the graphical abstract.

Keywords: ball-mill $\cdot$ green chemistry $\cdot$ mechanochemical reactions · N-heterocylic carbenes • silver • solvent-free reactions

[1] a) S. Budagumpi, R. A. Haque, S. Endud, G. U. Rehman, A. W. Salman, Eur. J. Inorg. Chem. 2013, 4367; b) W. Liu, R. Gust, Chem. Soc. Rev. 2013 , 42, 755; c) K. M. Hindi, M. J. Panzner, C. A. Tessier, C. L. Cannon, W. J. Youngs, Chem. Rev. 2009, 109, 3859.

[2] a) J. C. Garrison, W. J. Youngs, Chem. Rev. 2005, 105, 3978; b) E. Peris in $\mathrm{N}$-Heterocyclic Carbenes in Transition Metal Catalysis, Vol. 21 (Ed.: F. Glorius), Springer, Heidelberg, Germany, 2007, p.83; c) F.E. Hahn, M.C. Jahnke, Angew. Chem. Int. Ed. 2008, 47, 3122; Angew. Chem. 2008, 120 3166; d) M. C. Jahnke, F. E. Hahn, Top. Organomet. Chem. 2010, 30, 95; e) M. Melaimi, M. Soleilhavoup, G. Bertrand, Angew. Chem. Int. Ed. 2010, 49, 8810; Angew. Chem. 2010, 122, 8992.

[3] R. Visbal, M. C. Gimeno, Chem. Soc. Rev. 2014, 43, 3551.

[4] a) S. L. James, C. J. Adams, C. Bolm, D. Braga, P. Collier, T. Friščić, F. Grepioni, K. D. M. Harris, G. Hyett, W. Jones, A. Krebs, J. Mack, L. Maini, A. G. Orpen, I. P. Parkin, W. C. Shearouse, J. W. Steed, D. C. Waddell, Chem. Soc. Rev. 2012, 41, 413; b) G.-W. Wang, Chem. Soc. Rev. 2013, 42, 7668

[5] a) D. Braga, S. L. Giaffreda, F. Grepioni, A. Pettersen, L. Maini, M. Curzi, M. Polito, Dalton Trans. 2006, 1249; b) A. L. Garay, A. Pichon, S. L. James, Chem. Soc. Rev. 2007, 36, 846; c) T. Friščić, Chem. Soc. Rev. 2012, 41, 3493; d) E. Boldyreva, Chem. Soc. Rev. 2013, 42, 7719; e) M. Ferguson, N Giri, X. Huang, D. Apperley, S. L. James, Green Chem. 2014, 16, 1374; f) T. Friščić, in Ball Milling Towards Green Synthesis: Applications, Projects, Challenges, RSC, Cambridge, UK, 2015, p.151; g) D. Crawford, J. Casaban, R. Haydon, N. Giri, T. McNally, S. L. James, Chem. Sci. 2015, 6, 1645.
[6] a) V. Declerck, P. Nun, J. Martinez, F. Lamaty, Angew. Chem. Int. Ed. 2009 48, 9318; Angew. Chem. 2009, 121, 9482; b) T.-X. Métro, J. Bonnamour, T. Reidon, J. Sarpoulet, J. Martinez, F. Lamaty, Chem. Commun. 2012, 48, 11781 ; c) J. Bonnamour, T.-X. Métro, J. Martinez, F. Lamaty, Green Chem. 2013, 15, 1116; d) L. Konnert, A. Gauliard, F. Lamaty, J. Martinez, E. Colacino, ACS Sustainable Chem. Eng. 2013, 1, 1186; e) T.-X. Métro, X. J. Salom-Roig, M. Reverte, J. Martinez, F. Lamaty, Green Chem. 2015, 17, 204; f) T.-X. Métro, J. Bonnamour, T. Reidon, A. Duprez, J. Sarpoulet, J. Martinez, F. Lamaty, Chem. Eur. J. 2015, 21, 12787.

[7] V. Declerck, E. Colacino, X. Bantreil, J. Martinez, F. Lamaty, Chem Commun. 2012, 48, 11778.

[8] D. Prat, J. Hayler, A. Wells, Green Chem. 2014, 16, 4546.

[9] M. Hernández-Juárez, M. Vaquero, E. Álvarez, V. Salazar, A. Suárez, Dalton Trans. 2013, 42, 351.

[10] E. E. Alberto, A. L. Braga, M. R. Detty, Tetrahedron 2012, 68, 10476.

[11] W. Ochędzan-Siodłak, K. Dziubek, K. Czaja, Polym. Bull. 2013, 70, 1.

[12] L. Canovese, F. Visentin, C. Levi, C. Santo, V. Bertolasi, Inorg. Chim. Acta 2012, 390, 105.

[13] L. N. Appelhans, D. Zuccaccia, A. Kovacevic, A. R. Chianese, J. R. Miecznikowski, A. Macchioni, E. Clot, O. Eisenstein, R. H. Crabtree, J. Am. Chem. Soc. 2005, 127, 16299

[14] R. A. Haque, A. W. Salman, T. S. Guan, Aust. J. Basic Appl. Sci. 2011, 5, 365.

[15] D. Serra, P. Cao, J. Cabrera, R. Padilla, F. Rominger, M. Limbach, Organometallics 2011, 30, 1885.

[16] J. Z. Vlahakis, C. Lazar, I. E. Crandall, W. A. Szarek, Bioorg. Med. Chem. 2010, 18, 6184

[17] A. M. Magill, D. S. McGuinness, K. J. Cavell, G. J. P. Britovsek, V. C. Gibson, A. J. P. White, D. J. Williams, A. H. White, B. W. Skelton, J. Organomet. Chem. 2001, 617-618, 546.

[18] M. C. Jahnke, T. Pape, F. E. Hahn, Eur. J. Inorg. Chem. 2009, 1960.

[19] Calculation of various green metrics support lower environmental impact of this strategy compared to a solvent-based approach (See the Supporting Information for details).

[20] M. A. Mikhailenko, T. P. Shakhtshneider, V. V. Boldyrev, Mendeleev Commun. 2007, 17, 315

[21] a) P. F. M. Oliveira, M. Baron, A. Chamayou, C. Andre-Barres, B. Guidetti, M. Baltas, RSC Adv. 2014, 4, 56736; b) T. P. Shakhtshneider, V. Boldyrev, in Reactivity of Molecular Solids, Vol. 3 (Ed.: E. Boldyreva, V. Boldyrev), Wiley, Hoboken, USA, 1999, p. 271; c) M. Zbacnik, B. Kaitner, CrystEngComm 2014, 16, 4162; d) A. A. L. Michalchuk, I. A. Tumanov, V. A. Drebushchak, E. V. Boldyreva, Faraday Discuss. 2014, 170, 311; e) J. G. Hernández, T. Friščić, Tetrahedron Lett. 2015, 56, 4253.

[22] See the Supporting Information for details.

[23] L. Canovese, F. Visentin, C. Levi, C. Santo, V. Bertolasi, J. Organomet. Chem. 2013, 732, 27.

[24] X. Tang, C. Qi, H. He, H. Jiang, Y. Ren, G. Yuan, Adv. Synth. Catal. 2013, 355, 2019.

[25] L. Canovese, F. Visentin, C. Levi, C. Santo, Inorg. Chem. Commun. 2013, $32,74$.

[26] J. Berding, H. Kooijman, A. L. Spek, E. Bouwman, J. Organomet. Chem. 2009, 694, 2217.

[27] V. J. Catalano, M. A. Malwitz, Inorg. Chem. 2003, 42, 5483.

[28] CCDC $1404770\left(\left[\left\{\mathrm{Ag}(1 \mathrm{~b})_{2}\right\}^{+} \cdot \mathrm{AgBr}_{2}{ }^{-}\right]_{2}\right)$ contains the supplementary crystallographic data for this paper. These data are provided free of charge by The Cambridge Crystallographic Data Centre. 